\title{
Mutational spectrum of the EPM2A gene in progressive myoclonus epilepsy of Lafora: high degree of allelic heterogeneity and prevalence of deletions
}

\author{
Pilar Gómez-Garre ${ }^{1}$, Yolanda Sanz ${ }^{1}$, Santiago Rodríguez de Córdoba ${ }^{2,3}$ and \\ José M Serratosa ${ }^{1}$
}

\footnotetext{
${ }^{1}$ Servicio de Neurología, Fundación Jiménez Díaz; ${ }^{2}$ Unidad de Patalogía Molecular, Fundación Jiménez Díaz; ${ }^{3}$ Departmento de Inmunología, Centro de Investigaciones Biológicas, Consejo Superior de Investigaciones Científicas, Madrid, Spain
}

Progressive myoclonus epilepsy of the Lafora type (Lafora disease) is an autosomal recessive disease characterised by epilepsy, myoclonus, progressive neurological deterioration and the presence of glycogen-like intracellular inclusion bodies (Lafora bodies). We recently cloned the major gene for Lafora disease (EPM2A) and characterised the corresponding product, a putative protein tyrosine phosphatase (LAFPTPase). Here we report the complete coding sequence of the EPM 2A gene and the analysis of this gene in 68 Lafora disease chromosomes. We describe 11 novel mutations: three missense (F84L, G240S and P301L), one nonsense (Y86stop), three < 40 bp microdeletions (K90fs, Ex1-32bpdel, Ex1-33bpdel), and two deletions affecting the entire exon 1 (Ex1-del1 and Ex1-del2). In addition, we have identified three patients with a null allele in non-exonic microsatellites EPM 2A-3 or EPM2A-4, suggesting the presence of two distinct $>3 \mathbf{~ k b}$ deletions affecting exon 2 (Ex2-del1 and Ex2-del2). Considering these mutations, a total of 25 mutations, $60 \%$ of them generating truncations, have been described thus far in the EPM $2 A$ gene. In spite of this remarkable allelic heterogeneity, the R241stop EPM 2A mutation was found in approximately $40 \%$ of the Lafora disease patients. We also report the characterisation of five new microsatellite markers and one SNP in the EPM2A gene and describe the haplotypic associations of alleles at these sites in normal and EPM 2A chromosomes. This analysis suggests that both founder effect and recurrence have contributed to the relatively high prevalence of R241stop mutation in Spain. The data reported here represent the first systematic analysis of the mutational events in the EPM2A gene in Lafora disease patients and provide insight into the origin and evolution of the different EPM2A alleles. European Journal of Human Genetics (2000) 8, 946-954.

Keywords: mutation; polymorphism; EPM 2A; Lafora; progressive; epilepsy; PTPase; genetics; myoclonus

\section{Introduction}

Among the epilepsies, the progressive myoclonus epilepsies (PMEs) constitute a rare, heterogeneous subgroup characterised by the presence of progressive neurologic deterioration, myoclonus, and epilepsy. ${ }^{1}$ PME of the Lafora type or Lafora disease (EPM2 [MIM 254780]) is a well known form of

Correspondence: José M Serratosa, MD, PhD, Servicio de Neurología, Fundación Jiménez Díaz, Avda Reyes Católicos, 2, 28040 Madrid, Spain. Tel: +3491550 4854; Fax: +34915497381; E-mail: serratosa@jet.es Received 13 March 2000; revised 7 August 2000; accepted 23 August 2000 progressive myoclonus epilepsy characterised by the presence of typical periodic acid Schiff-positive intracellular inclusion bodies (Lafora bodies). ${ }^{2,3}$ Lafora bodies consist of an abnormal glucose polymer that accumulates in the central and peripheral nervous system, among other tissues. ${ }^{4,5}$ Lafora disease initially manifests during adolescence, the most common age of onset being between 10 and 17 years. Generalised tonic-clonic seizures, absences, drop attacks, or partial visual seizures are usually the first manifestation, followed soon after by asymmetric as well as massive myoclonic jerks. As the disease progresses, the myoclonus 
increases in frequency and becomes constant. A rapidly progressive dementia with apraxia, aphasia, and visual loss ensues, leading patients to a vegetative stage and death, usually within less than a decade of first symptoms. ${ }^{6}$ Lafora disease occurs worldwide, but is particularly common in the Mediterranean countries of Southern Europe and Northern Africa, in Southern India and in the Middle East. As in other autosomal recessive diseases, consanguinity is common in Lafora disease. Linkage analysis and homozygosity mapping first localised a major gene for Lafora disease to chromosome $6 q 24 .^{7}$ However, other gene or genes than EPM 2A may cause Lafora disease when mutated, since in approximately $10-20 \%$ of the families linkage to chromosome 6 q24 can be excluded. ${ }^{8,9}$ Recently, we and others have cloned the EPM $2 \mathrm{~A}$ gene and have shown that affected individuals were homozygous or compound heterozygous for loss-of-function mutations. ${ }^{10,11}$

The human EPM2A gene spans approximately $70 \mathrm{~kb}$ and codes for a transcript of about $3 \mathrm{~kb}$ which is split into 4 exons ranging from 112 to $2328 \mathrm{bp}^{10,11}$ Exon 4 includes two alternative splicing transcripts ( 4 and $4 \mathrm{~b}$ ) (Figures 1 and 2 ).

Here we have investigated the EPM $2 \mathrm{~A}$ gene in 68 Lafora disease chromosomes from 34 unrelated patients and in 126 normal chromosomes of Spanish origin. We report the detection of 11 novel EPM $2 \mathrm{~A}$ mutations and the characterisation of several EPM 2A polymorphisms. The analysis of the associations between the EPM 2A mutations and the EPM 2A polymorphisms provides useful data for population genetic studies and for investigating the history of the EPM $2 \mathrm{~A}$ mutations.

\section{Materials and methods \\ Patients}

The clinical diagnosis of Lafora disease was based on the presentation of epilepsy, myoclonus, rapidly progressive neurological deterioration, and a slow background with polyspike-wave complexes in the electroencephalogram. ${ }^{6,12}$ In addition, we required a biopsy of skin, muscle, liver, or brain showing the characteristic periodic acid Schiff-positive Lafora bodies. ${ }^{2,3}$ Information on age of onset was available from 29 patients belonging to 19 families. Age of onset ranged from 4 to 16 years (mean $=12$ years). The first symptom of the disease was either generalised tonic-clonic seizures, absences, or simple partial seizures with visual symptoms. The severity of the myoclonus was mild at onset and increased in severity as the disease progressed. Progressive dementia followed in all patients. All families included in this study were genotyped with the chromosome $6 q 24$ microsatellites markers contained in the region of the Lafora disease's gene; 30 families showed segregation of markers flanking EPM 2A with the Lafora disease phenotype and four were not informative because of the low number of available family members. Five families in which linkage to chromosome6q24 markers could be excluded were not included in this study. These families represent $13 \%$ of our Lafora disease family database.

\section{Samples}

Thirty-four affected probands were included in this study. The patients originated from Spain, Italy, Australia, Holland, the United States of America, North Africa, Turkey, and France. Forty-eight healthy Spanish individuals were screened to verify that the mutations found were absent in the normal population. To calculate allele frequencies at the EPM2A polymorphic sites and to estimate haplotype frequencies we used 126 control chromosomes. DNA samples were obtained from peripheral blood lymphocytes, using standard methods. The study was approved by the Ethics Committee of the Fundación Jiménez Díaz. Blood was collected from patients and their relatives after informed consent.

\section{PCR amplification and sequencing of exons}

Exons 1, 2, 3 and 4 of the EPM 2A gene ${ }^{11}$ were amplified from genomic DNA using specific primers derived from 5' and 3' intronic sequences (Table1) using standard methods. The initiating ATG of exon 1 was obtained by PCR amplification from a human placenta CDNA (Clontech, Palo Alto, CA, USA). The annealing temperature for all primer pairs was $60^{\circ} \mathrm{C}$. The corresponding PCR products were purified by agarose gel electrophoresis and extracted with the Qiaquick Gel Extraction Kit (Qiagen, Hilden, Germany). Direct sequencing of PCR products was performed with a dyeterminator cycle-sequencing kit (Perkin-Elmer, Warrington, UK) using Taq FS DNA polymerase. Sequences were resolved on an ABI PRISM 377 automatic sequencer, and the results analysed with the ABI Analysis software (version 3.1).

\section{Microsatellite analysis}

Analysis of polymorphisms at the EPM 2A-1, EPM2A-2, EPM2A-3, EPM2A-4, EPM 2A-5, and D6S1703 microsatellites was performed by PCR, using total human genomic DNA. Amplification was performed in a total volume of $10 \mu \mathrm{l}$ containing $40 \mathrm{ng}$ of genomic DNA, 3 pmol of each primer (Table2), 0.3U Taq polymerase (Promega, Madison, WI, USA), $200 \mu \mathrm{M}$ each dATP, dGTP and dTTP, $2.5 \mu \mathrm{M}$ dCTP, $0.7 \mu \mathrm{Ci}\left[{ }^{32} \mathrm{P}\right] \alpha-\mathrm{dCTP}$ at $300 \mathrm{Ci} \mathrm{mmol}{ }^{-1}$, and $1.5 \mathrm{~mm} \mathrm{MgCl}_{2}$. $\mathrm{PCR}$ conditions were one cycle at $94^{\circ} \mathrm{C}$ for $2 \mathrm{~min}$, followed by $30 \mathrm{cycles}$ of $94^{\circ} \mathrm{C}$ for $30 \mathrm{~s}, 55.5^{\circ} \mathrm{C}$ for $1 \mathrm{~min}$, and $74^{\circ} \mathrm{C}$ for $15 \mathrm{~s}$, and one last cycle of $74^{\circ} \mathrm{C}$ for $6 \mathrm{~min}$. Samples were resolved on a $6.5 \%$ polyacrylamide sequencing gels and exposed on Kodak XAR film for $1-14 \mathrm{~h}$.

\section{SSCP analysis}

SSCP analysis ${ }^{13}$ was performed by PCR, using total genomic DNA, using the GenePhor DNA Electrophoresis System (Amersham Pharmacia Biotech, Uppsala, Sweden). Amplification was performed in a total volume of $10 \mu$ l containing $60 \mathrm{ng}$ of genomic DNA, $12.5 \mathrm{pmol}$ of each primer (Table 3 ), $1 \mathrm{U}$ of Taq polymerase (Promega), $200 \mu \mathrm{m}$ each dATP, dCTP, 


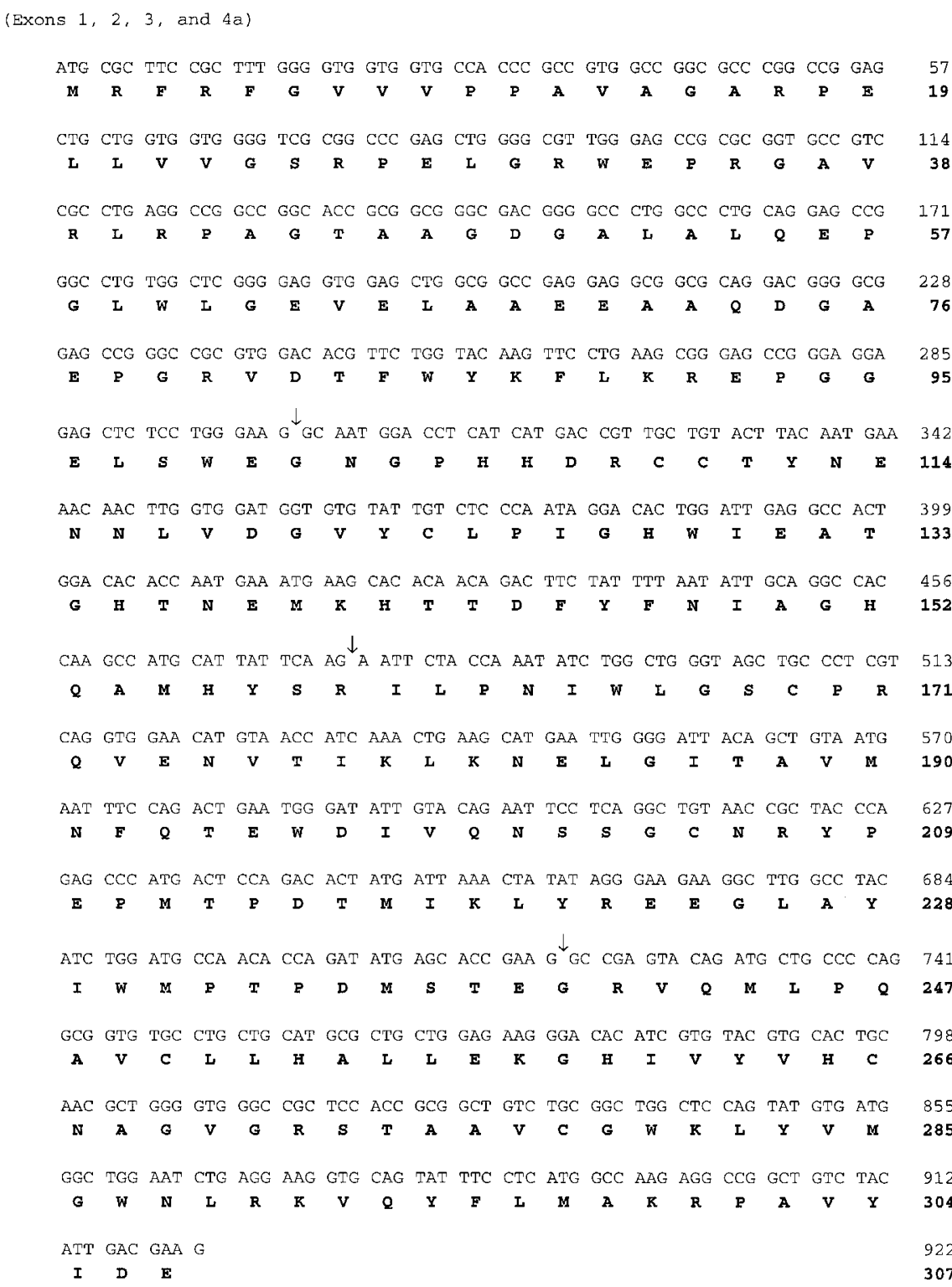

(Exon 4)

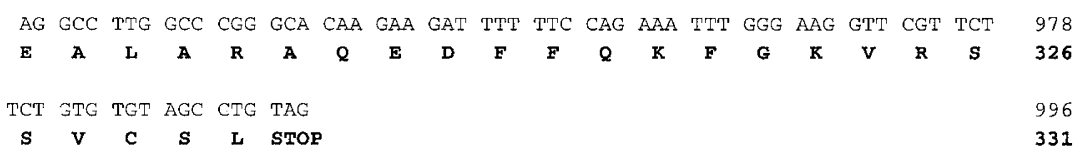

(Exon $4 b$ )

$\begin{array}{llllllllllll}\text { AG } & \text { GCA } & \text { GCT } & \text { AGC } & \text { CAG } & \text { CAG } & \text { ACA } & \text { TTT } & \text { CCA } & \text { CTA } & \text { TAA } & 954 \\ \mathbf{E} & \mathbf{A} & \mathbf{A} & \mathbf{S} & \mathbf{Q} & \mathbf{D} & \mathbf{T} & \mathbf{F} & \mathbf{P} & \mathbf{L} & \text { STOP } & \mathbf{3 1 7}\end{array}$

Figure 1 CDNA sequence and derived amino acid sequence of EPM2A. Nucleotide sequence of the CDNA corresponding to EPM2A exons 1, 2, 3 and 4. Exon junctions are indicated with small vertical arrows. The conceptual translation of the EPM 2A ORF is shown below the cDNA sequence in one-letter code. The sequence begins with the translation ATG start codon.

dGTP and dTTP, and $1.5 \mathrm{~mm} \mathrm{MgCl}_{2}$. PCR conditions were one cycle at $94^{\circ} \mathrm{C}$ for $2 \mathrm{~min}$, followed by 30 cycles of $94^{\circ} \mathrm{C}$ for min, $60^{\circ} \mathrm{C}$ for $1 \mathrm{~min}$, and $74^{\circ} \mathrm{C} 1 \mathrm{~min}$, one cycle of $74^{\circ} \mathrm{C}$ for $3 \mathrm{~min}$ and one last cycle of $25^{\circ} \mathrm{C}$ for 2 min. Samples were resolved on $12.5 \%$ non-denaturing polyacrilamide gels with the GeneGel Excel 12.5/24 kit (Amersham Pharmacia Biotech) 


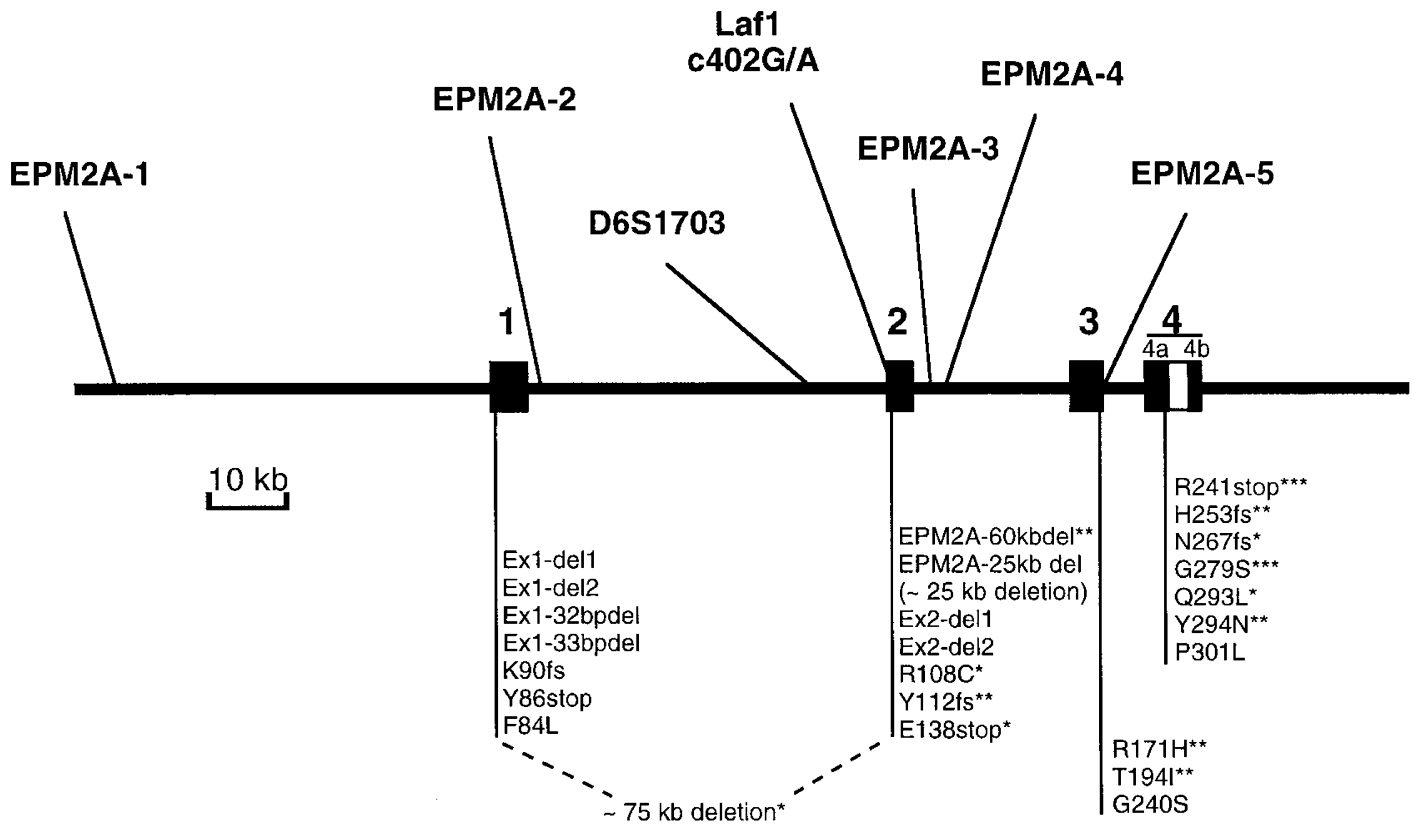

Figure 2 Localisation of EPM 2A mutations and associated polymorphic markers at the human EPM2A locus. The human EPM 2A gene is shown as a horizontal line, with the exons indicated by short, thick vertical lines and labelled 1-4. Exon 4 includes two alternative splicing transcripts: one includes the complete exon 4 and presents a stop codon $75 \mathrm{bp}$ after the end of segment $4 \mathrm{a}$; the other one is formed by segments $4 \mathrm{a}$ and $4 \mathrm{~b}$ and lacks the central part of exon 4 . Below the structure of the EPM $2 \mathrm{~A}$ gene, the thin lines localise the position of each of the 25 EPM $2 \mathrm{~A}$ mutations characterised so far. Above the structure of the EPM $2 \mathrm{~A}$ gene, the thin lines show the relative positions of seven polymorphic sites: EPM2A-1, EPM2A-2, EPM2A-3, EPM2A-4, EPM2A-5, and D6S1703 are SSRs; Laf-1 is a SNP. EPM $2 A-25 \mathrm{kbdel}$ and $\sim 25 \mathrm{~kb}$ deletion ${ }^{16}$ may be the same mutation; *from reference $10 ; * *$ from reference $11 ; * * *$ from both references 10 and 11 .

and silver staining using the PlusOne ${ }^{\mathrm{TM}}$ DNA Silver Staining kit (Amersham Pharmacia Biotech).

\section{Mutation hot spot analysis}

Identification of potential mutation hot spots was performed with the computer program MUTPRED, which is based on empirical data and designed to predict the location of point mutations within gene coding regions causing human genetic disease. $^{14}$

\section{References for links using databases}

The major gene for Lafora disease codes the LAFPTPase, a putative protein tyrosine phosphatase (PTPase). ${ }^{11}$ The nucleotide sequences for the human EPM 2A gene have been deposited under EMBL/GenBank accession numbers AJ 130763, AJ130764, and AF084535.

\section{Results \\ Initiating ATG of exon 1}

The human EPM 2A gene codes for a transcript of about $3 \mathrm{~kb}$ for which the $5^{\prime}$ end sequence was only partially characterised in humans. ${ }^{10,11}$ Here we report the complete coding sequence of the EPM $2 A$ gene including the ATG initiation codon region (Figure1). We obtained a $450 \mathrm{bp}$ PCR fragment from a human placenta cDNA covering the complete exon 1 and part of exon 2 . This fragment contained an ATG codon 241 bp upstream from the beginning of the consensus CDNA sequence we proposed in our initial cloning report and extends the previously communicated sequence of exon $1 .^{10,11}$ The presence of an in-frame stop codon 66 nucleotides before this ATG codon and the high sequence identity with the murine ATG translation initiation codon

Table 1 PCR primers for genomic amplification of the EPM $2 A$ exons $\left(5^{\prime} \rightarrow 3^{\prime}\right)$ for sequencing

\begin{tabular}{lll}
\hline Exon & Primer forward & Primer reverse \\
\hline 1 & TGCGCTTCCGCTTTGGG & AGGGACGCGGGCAAAAAGC \\
2 & GTATCAGCTGCTTGAGGATA & CTTGTCCTACTTCTATGCCTA \\
3 & CTACATGTTTATGCAGCTCC & ATTTATTCCATTCTACCATTCAT \\
4 & GAGAGAGCCTCTGGCCTC & CAGAAGAACGAACCTTCCCA \\
\hline
\end{tabular}


Table 2 Novel polymorphic markers within the EPM 2A gene

\begin{tabular}{|c|c|c|c|c|c|c|c|}
\hline Marker & $I D^{a}$ & Type & Het $^{b}$ & Primers $\left(5^{\prime} \rightarrow 3^{\prime}\right)$ & Allele & $\mathrm{FQ} 1^{\mathrm{C}}$ & $\mathrm{FQ} 2^{\mathrm{d}}$ \\
\hline EPM 2A-1 & 9992791 & $(C A) n$ & 0.746 & $\begin{array}{ll}\text { F: } & \text { CTCCTTGCTTCTCAAGCTT } \\
\text { R: } & \text { TGGACTTACAGAATGCTTATA }\end{array}$ & $\begin{array}{l}175 \\
177 \\
179 \\
181 \\
183 \\
185 \\
187 \\
189 \\
191 \\
193 \\
195\end{array}$ & $\begin{array}{l}0.008 \\
0.016 \\
0.016 \\
0.008 \\
0.057 \\
0.074 \\
0.377 \\
0.303 \\
0.082 \\
0.041 \\
0.016\end{array}$ & $\begin{array}{l}0.020 \\
0.040 \\
0.040 \\
0.020 \\
0.020 \\
0.040 \\
0.180 \\
0.500 \\
0.100 \\
0.040 \\
0.000\end{array}$ \\
\hline EPM 2A-2 & 9992793 & $(C A) n$ & 0.725 & $\begin{array}{l}\text { F: CTCATAATCCTATTATGCAGGA } \\
\text { R: AAAGTCTCAGGTTACAGCTAA }\end{array}$ & $\begin{array}{l}152 \\
154 \\
156 \\
158 \\
160 \\
162 \\
164 \\
166 \\
168 \\
170\end{array}$ & $\begin{array}{l}0.008 \\
0.083 \\
0.008 \\
0.275 \\
0.042 \\
0.075 \\
0.042 \\
0.417 \\
0.050 \\
0.000\end{array}$ & $\begin{array}{l}0.020 \\
0.059 \\
0.020 \\
0.196 \\
0.078 \\
0.196 \\
0.059 \\
0.451 \\
0.020 \\
0.020\end{array}$ \\
\hline EPM 2A-3 & 9992834 & $(C A) n$ & 0.851 & $\begin{array}{l}\text { F: GTGTATGTATACCTGGAGTATAA } \\
\text { R: GATAAATCATAACATGGAATGG }\end{array}$ & $\begin{array}{l}134 \\
136 \\
138 \\
140 \\
142 \\
144 \\
146 \\
148 \\
150 \\
152 \\
154 \\
156 \\
158 \\
160\end{array}$ & $\begin{array}{l}0.057 \\
0.156 \\
0.229 \\
0.016 \\
0.033 \\
0.066 \\
0.180 \\
0.123 \\
0.049 \\
0.049 \\
0.033 \\
0.008 \\
0.000 \\
0.000\end{array}$ & $\begin{array}{l}0.061 \\
0.041 \\
0.306 \\
0.020 \\
0.020 \\
0.082 \\
0.102 \\
0.143 \\
0.000 \\
0.020 \\
0.000 \\
0.020 \\
0.061 \\
0.122\end{array}$ \\
\hline EPM 2A-4 & 9992864 & (AAAT)n & 0.518 & $\begin{array}{l}\text { F: ATGTAACTAACCTGCACATTGTG } \\
\text { R: GATAAATCATAACATGGAATGG }\end{array}$ & $\begin{array}{l}143 \\
151 \\
157 \\
159 \\
167\end{array}$ & $\begin{array}{l}0.051 \\
0.393 \\
0.000 \\
0.530 \\
0.026\end{array}$ & $\begin{array}{l}0.000 \\
0.275 \\
0.039 \\
0.686 \\
0.000\end{array}$ \\
\hline EPM 2A-5 & 9992874 & $($ TGTC)n & 0.102 & $\begin{array}{l}\text { F: CCATGACTCCAGACACTATG } \\
\text { R: TTTATTCCATTTCTACCATTCAT }\end{array}$ & $\begin{array}{l}199 \\
195\end{array}$ & $\begin{array}{l}0.986 \\
0.014\end{array}$ & $\begin{array}{l}0.906 \\
0.094\end{array}$ \\
\hline Laf-1 & - & $\begin{array}{l}\mathrm{C} 402 \mathrm{G} \rightarrow \mathrm{A} \\
(\mathrm{G} 134 \mathrm{G})\end{array}$ & 0.219 & $\begin{array}{l}\mathrm{F}: \text { GTATCAGCTGCTTGAGGATA } \\
\mathrm{R}: \text { CTTGTCCTACTTCTATGCCTA }\end{array}$ & $\begin{array}{l}\mathrm{G} \\
\mathrm{A}\end{array}$ & $\begin{array}{l}0.783 \\
0.217\end{array}$ & $\begin{array}{l}0.594 \\
0.406\end{array}$ \\
\hline
\end{tabular}

aID: accession number from Généthon; ${ }^{\text {} H e t: ~ c a l c u l a t e d ~ h e t e r o z y g o s i t y ; ~}{ }^{\mathrm{c}} \mathrm{FQ} 1$ : allele frequency in normal population; ${ }^{\mathrm{d} F Q 2:}$ allele frequency in affected population.

region ${ }^{15}$ suggests that this is the ATG translation initiation codon in EPM2A. In addition, the length of the mRNA present in northern blots is in agreement with this ATG being the initiation codon.

\section{Mutations in EPM2A}

In our previous study reporting the identification of the EPM 2A gene we described the mutational analysis of the EPM 2A gene in 20 Lafora disease pedigrees that resulted in the identification of 13 Lafora disease chromosomes carrying a total of eight different EPM2A mutations. ${ }^{11}$ Probably because those mutational studies were incomplete and focused only on EPM $2 A$ exons2, 3 and $4 a$, we failed to identify EPM 2A mutations in $70 \%$ of the Lafora disease chromosomes. In this report 68 chromosomes from 34 unrelated Lafora disease patients, including those partially characterised before, were screened for mutations in the EPM $2 \mathrm{~A}$ gene. This time, all four exons of the EPM 2A gene, including their flanking intronic sequences, were amplified from genomic DNA of each Lafora disease patient, using the PCR primers specified in Table1. SSCP analysis was performed for all exons and those presenting band shifts were subsequently sequenced in both strands. 
Table 3 PCR primers for SSCP analysis of the EPM 2A gene

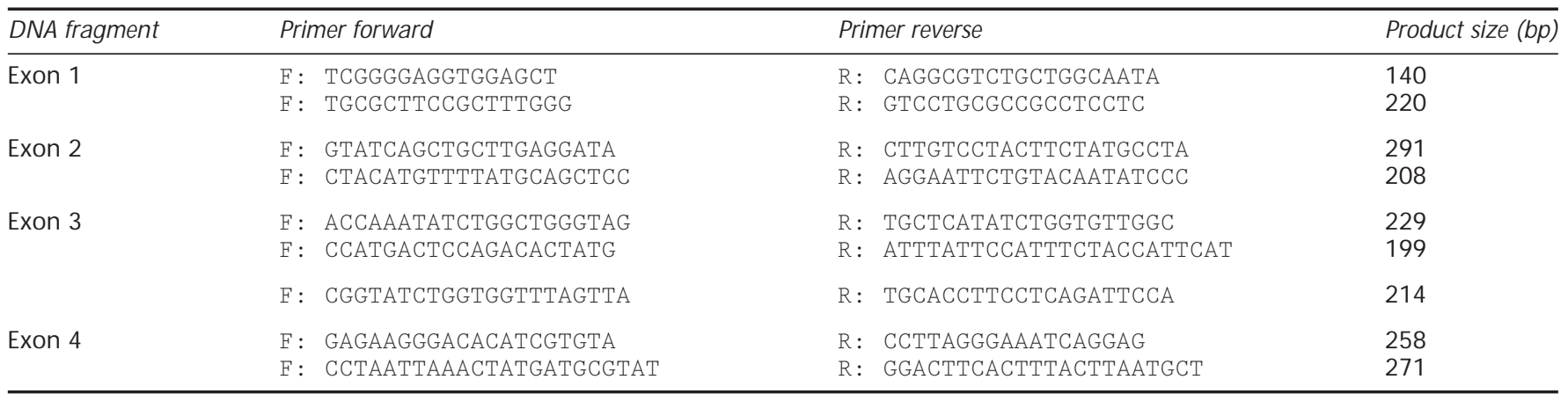

The analysis of the 68 chromosomes from 34 Lafora disease probands resulted in the identification of EPM $2 \mathrm{~A}$ mutations in 49 of them (72\%). Twenty-three probands presented mutations in both chromosomes (affected individuals were homozygous or double heterozygous). In four probands mutations were identified in only one of the two copies of the EPM 2A gene. Therefore, the total number of families presenting EPM 2 A mutations was 27 (79\%). It is thus possible that 7 of the 34 families from this study harbour mutations in a non-EPM 2A gene since no mutated alleles were identified in these families. However, the existence of four families where mutations have been identified in only one chromosome supports the idea that there are indeed unidentified mutations.

A total of 20EPM2A mutations, 11 of them novel, were characterised (Figure 2 and Table4). Mendelian inheritance of the mutations was confirmed by SSCP and sequence analysis of the relevant amplified DNA fragment in family

Table 4 EPM 2A mutations identified in Lafora disease patients

\begin{tabular}{|c|c|c|c|c|c|c|c|c|}
\hline Mutation & Exon & Type & $\begin{array}{l}\text { Nucleotide } \\
\text { change }\end{array}$ & $\begin{array}{l}\text { Amino acid change/ } \\
\text { predicted consequence }\end{array}$ & $\begin{array}{l}\text { No. of } \\
\text { chromo- } \\
\text { somes }\end{array}$ & $\begin{array}{l}\text { No. of } \\
\text { probands }\end{array}$ & $\begin{array}{l}\text { Country } \\
\text { of origin }\end{array}$ & Reference \\
\hline Ex1-del1 & 1 & deletion & deletion exon 1 & Truncation at exon 2 & 1 & 1 & Spain & Present report \\
\hline Ex1-del2 & 1 & deletion & deletion exon 1 & Truncation at exon 2 & 1 & 1 & Spain & Present report \\
\hline Ex1-33bpdel & 1 & microdeletion & c.91-123del & Truncation after gly 30 & 3 & 2 & Spain & Present report \\
\hline Ex1-32bpdel & 1 & microdeletion & c.102-133del & Truncation after gly 36 & 2 & 2 & Spaln & Present report \\
\hline F84L & 1 & missense & C. $252 \mathrm{C} \rightarrow \mathrm{G}$ & phe 84 leu & 2 & 1 & France & Present report \\
\hline Y86stop & 1 & nonsense & C. $258 C \rightarrow G$ & tyr 86 Stop & 2 & 1 & Spain & Present report \\
\hline K90fs & 1 & frameshift & c. $269-275 \mathrm{del}$ & Truncation after lys 90 & 2 & 1 & Holland & Present report \\
\hline R108C & 2 & missense & c. $322 \mathrm{C} \rightarrow \mathrm{T}$ & arg 108 cys & $\begin{array}{l}2 \\
2\end{array}$ & $\begin{array}{l}1 \\
1\end{array}$ & Spain & $\begin{array}{l}\text { Present report } \\
\text { Minassian et al }{ }^{10}\end{array}$ \\
\hline Y112fs & 2 & frameshift & c.335-336insA & Truncation after thr 112 & 2 & 1 & Italy & Serratosa et $a^{11}$ \\
\hline E138stop & 2 & nonsense & c. $412 \mathrm{G} \rightarrow \mathrm{T}$ & glu 138 Stop & 2 & 1 & - & Minassian et al ${ }^{10}$ \\
\hline EPM 2A-60kbdel & 2 & deletion & deletion exon 2 & Truncation at exon 3 & 2 & 1 & Italy & Serratosa et al ${ }^{11}$ \\
\hline EPM 2A-25kbdel & 2 & deletion & deletion exon 2 & Truncation at exon 3 & $\begin{array}{l}2 \\
2\end{array}$ & $\begin{array}{l}1 \\
1\end{array}$ & $\begin{array}{l}\text { USA } \\
\text { Iran }\end{array}$ & $\begin{array}{l}\text { Present report } \\
\text { Minassian et al }\end{array}$ \\
\hline Ex2-del1 & 2 & deletion & deletion exon 2 & Truncation at exon 3 & 1 & 1 & USA & Present report \\
\hline $\mathrm{R} 171 \mathrm{H}$ & 3 & missense & C. $512 \mathrm{G} \rightarrow \mathrm{A}$ & arg 171 his & 1 & 1 & USA & Serratosa et al ${ }^{11}$ \\
\hline T194I & 3 & missense & C. $581 C \rightarrow T$ & thr 194 ile & 1 & 1 & Spain & Serratosa et al ${ }^{11}$ \\
\hline G240S & 3 & missense & C. $718 \mathrm{G} \rightarrow \mathrm{A}$ & gly 240 lys & 1 & 1 & Australia & Present report \\
\hline R241stop & 4 & nonsense & C. $721 \mathrm{C} \rightarrow \mathrm{T}$ & arg 241 Stop & $\begin{array}{l}13 \\
1 \\
2 \\
9\end{array}$ & $\begin{array}{l}10 \\
1 \\
1 \\
5\end{array}$ & $\begin{array}{l}\text { Spain } \\
\text { Italy } \\
\text { Turkey } \\
\text { - }\end{array}$ & Serratosa et al ${ }^{11}$ \\
\hline N267fs & 4 & frameshift & c. 799-800insA & Truncation after asn 267 & 2 & 1 & - & Minassian et al ${ }^{10}$ \\
\hline H253fs & 4 & frameshift & c. $759 \mathrm{~T} \rightarrow$ CATGCA & Truncation after his 253 & 1 & 1 & Australia & Serratosa et al ${ }^{11}$ \\
\hline G279S & 4 & missense & c. $835 \mathrm{G} \rightarrow \mathrm{A}$ & gly 279 ser & $\begin{array}{l}2 \\
2\end{array}$ & $\begin{array}{l}2 \\
2\end{array}$ & $\begin{array}{l}\text { Spain } \\
\text { Italy }\end{array}$ & Serratosa et al ${ }^{11}$ \\
\hline & & & & & 1 & 1 & - & Minassian et al ${ }^{10}$ \\
\hline Q293L & 4 & missense & C. $878 \mathrm{~A} \rightarrow \mathrm{T}$ & gln 293 leu & 2 & 1 & - & Minassian et al ${ }^{10}$ \\
\hline Y294N & 4 & missense & C. $880 \mathrm{~T} \rightarrow \mathrm{A}$ & tyr 294 asn & 1 & 1 & Spain & Serratosa et al ${ }^{11}$ \\
\hline P301L & 4 & missense & C. $902 \mathrm{C} \rightarrow \mathrm{T}$ & pro 301 leu & 1 & 1 & France & Present report \\
\hline about $75 \mathrm{kbdel}$ & & deletion & $\begin{array}{l}\text { deletion } \\
\text { exons } 1 \text { and } 2\end{array}$ & Truncation in exon 3 & 2 & 1 & - & $\begin{array}{l}\text { Minassian et al } \\
\text { Minassian et }{ }^{10}\end{array}$ \\
\hline
\end{tabular}


members. One of the novel mutations is a $32 \mathrm{bp}$ deletion (c.102-133del) affecting the ATG region of exon 1 and resulting in a stop codon in exon 2 . This mutation confirms that this region is part of the EPM 2A transcript.

Three of the novel mutations reported here are missense mutations, resulting in the following amino acid substitutions: F84L, G240S and P301L. We do not know yet whether these mutations are loss-of-function mutations. However, our control population of unaffected unrelated individuals, which included 96 chromosomes, showed none of these mutations, suggesting that these changes do not represent polymorphisms in our population. Another novel mutation, Y86stop, is a nonsense mutation; three are deletions of less than $40 \mathrm{bp}$ (K90fs, Ex1-32bpdel, Ex1-33bpdel); two are deletions of yet undetermined size affecting exon 1 (Ex1-del 1 and Ex1-del2); and two are $>3 \mathrm{~kb}$ deletions that include exon 2 (Ex2-del1, Ex2-del2). In a recent report ${ }^{16}$ a new mutation has been communicated: a $25 \mathrm{~kb}$ deletion affecting exon 2 which may be identical to a $25 \mathrm{~kb}$ deletion we have identified and denote EPM $2 \mathrm{~A}-25 \mathrm{kbdel}$.

Adding these data to those reported earlier, ${ }^{10,11,16}$ a total of 25 EPM 2A mutations have been identified in 44 unrelated Lafora disease patients. Nine of the EPM 2A mutations are missense mutations, three are nonsense mutations, three are frameshift mutations, and ten are deletions of the different sizes (Table4). The R241stop mutation was encountered in almost $40 \%$ of the Lafora disease probands.

\section{Polymorphic sites in the EPM2A region}

Here we describe the identification and analysis of six novel polymorphic sites at the EPM 2A locus. These novel polymorphic sites correspond to three variable dinucleotide repeats (EPM 2A-1, EPM 2A-2 and EPM 2A-3), two variable tetranucleotide repeats (EPM2A-4 and EPM2A-5), and one SNP (Laf-1). The localisation of each simple sequence repeat (SSR) and SNP within the EPM 2A region is shown in Figure2. All five SSRs were encountered by inspection of a 100-kb-long sequence of the $150 \mathrm{~kb} 466 \mathrm{P} 17$ clone (The Sanger Centre, Cambridge, UK) encompassing exons 1-2 and by sequencing part of intron 3. EPM 2A-1, EPM 2A-2, and EPM 2A-3 are perfect $(C A)_{n}$ repeats. EPM $2 A-4$ is a perfect $(A A A T)_{n}$ repeat and EPM $2 A-5$ is a $(\text { TGTC })_{2-3}$ repeat. EPM 2A-1 is located $50.5 \mathrm{~kb}$ upstream the $5^{\prime}$ end of exon 1, EPM 2A-2 is located $2866 \mathrm{bp}$ downstream of the $3^{\prime}$ end of exon 1, EPM $2 A-3$ is located $2767 \mathrm{bp}$ downstream of the $3^{\prime}$ end of exon 2, and EPM 2A-4 is located 2763 bp downstream of EPM 2A-3 in intron 2. EPM 2A-5 is a rare polymorphism located in the $5^{\prime}$ end of intron 3. During SSCP mutation analysis experiments, we found one SNP (c.402G/A in exon 2) which we excluded from being an EPM 2A mutation because it was present in the normal population (in heterozygosis and homozygosis) and represents no change in the aminoacid sequence. The allele frequencies of these six novel polymorphisms in Lafora disease patients and in the control population are shown in Table2.

\section{Haplotype analysis of polymorphic sites within the EPM2A gene}

Haplotype associations between alleles at seven polymorphic sites within or near the EPM 2A gene were established for a total of 126 control chromosomes. This analysis included the D6S1703 site, a microsatellite from the Généthon collection. ${ }^{17}$ The haplotypes generated from this small sample of chromosomes are almost all unique.

To establish the haplotypic associations between EPM 2A polymorphisms and EPM $2 A$ mutations, all seven polymorphic markers (EPM2A-1, EPM2A-2, D6S1703, Laf-1, EPM 2A-3, EPM 2A-4, and EPM2A-5) were characterised in the Lafora disease probands and their families. We observed that there are five different haplotypes associated with the R241stop mutation (Table5). One of them is present in 10 of 16 Lafora disease chromosomes carrying this mutation. The second most common mutation, G279S, appears associated with three different haplotypes. These data suggest that both R241stop and G279stop are recurrent mutations. In addition, these data indicate that the high prevalence of the R241stop mutation is a consequence of both founder effect and recurrence. All other mutations are present in three or less Lafora disease chromosomes and are associated each to only one hapl otype. A complete description of the EPM2A haplotypes for 47EPM 2A chromosomes where a mutation has been identified, including 13Lafora disease chromosomes reported in our initial communication, ${ }^{11}$ is presented in Table5.

\section{Discussion}

We and others reported, elsewhere, that a gene coding a protein tyrosine phosphatase (PTPase) is the gene for $6 q$-linked Lafora disease. ${ }^{10,11}$ In the two initial reports the partially characterised 5 ' end of the gene and 13 different mutations were communicated. We described eight mutations in our Lafora disease family set, but failed to identify EPM 2A mutations in $70 \%$ of the affected Lafora disease chromosomes because of the incompleteness of our preliminary study. In this report we describe the sequence of exon 1 containing the ATG translation initiation codon and the systematic mutational analysis of the EPM $2 \mathrm{~A}$ gene in 68 chromosomes from 34 unrelated Lafora disease probands. In this sample we have identified a total of 20EPM 2A mutations, eleven of them novel, and have characterised the EPM $2 A$ haplotypes associated with each EPM2A mutation.

Five of the 11 novel mutations described here are deletions affecting a few nucleotides or even entire exons. Ex1-32bpdel is a deletion (c.102-133del) resulting in a frameshift after Gly36 that results in the posterior truncation of the protein. Ex1-del1, Ex1-del2, Ex2-del1, and Ex2 del2 are deletions affecting entire exons ( 1 or 2 ). All these deletions result in truncation of the EPM $2 \mathrm{~A}$ gene product. Y86stop is a nonsense mutation (c. $258 \mathrm{C} \rightarrow \mathrm{G}$ ) that results in a stop codon and, thus, in a truncated protein as well. Ex1-33bpdel is a deletion resulting in the substitution of one amino acid and the 
Table 5 EPM2A haplotypes associated with EPM 2A mutations

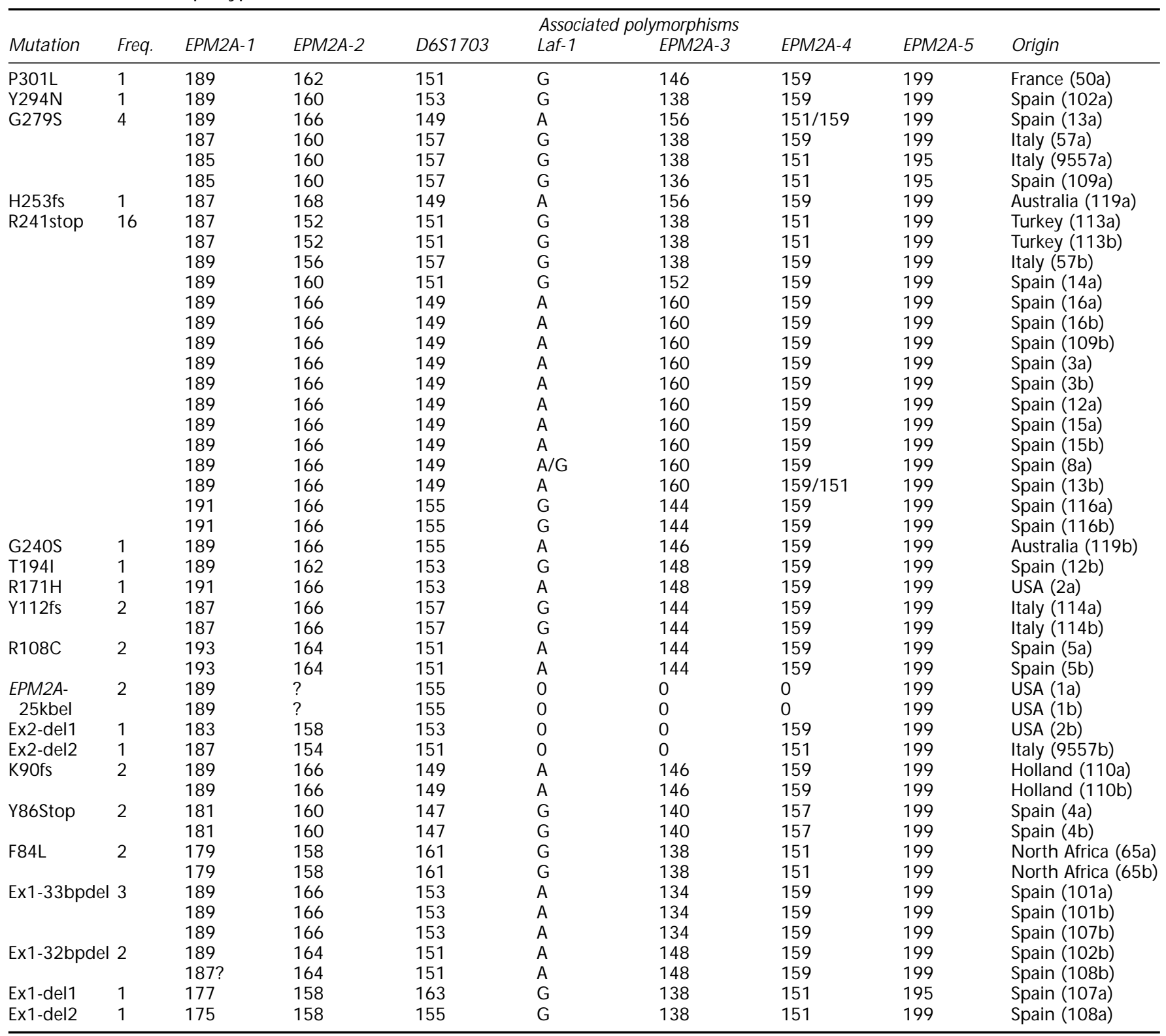

elimination of the subsequent ten amino acids without producing a posterior frameshift. K90fs is a mutation found in homozygosis in a patient born of a consanguineous mating. This mutation is the consequence of a sevennucleotide deletion in exon 1 (c.269-275del).

Therefore, eight of the novel EPM2A mutations result in truncated polypeptides that are most likely non-functional. The consequences of the other three novel mutations are more difficult to foresee. F84L, G240S, and P301L are missense resulting in changes of amino acids in different exons. F84L is a mutation carried in homozygosis by one patient from a consanguineous family that results from the substitution c.252C $\rightarrow$ G in exon 1. G240S (c.718G $\rightarrow A$ ) was found in one patient who carries the H253fs insertional substitution (c.759T $\rightarrow$ CATGCA) in the other Lafora disease chromosome. $\mathrm{P} 301 \mathrm{~L}$ is the consequence of the c.902C $\rightarrow T$ substitution and was also identified in heterozygosis. All novel mutations described here were not found in a sample of 96 unaffected chromosomes, indicating that they are not polymorphisms.

As a whole, 25 different mutations in EPM 2A have been identified in 46 unrelated Lafora disease patients (including those described elsewhere, ${ }^{10,11,16}$ and in this report). These mutations are distributed throughout the whole length of the EPM 2A gene sequence (Figure 2, Table4). It is noticeable, however, that the occurrence of missense mutations in 
EPM 2A (36\%) is somehow reduced compared with that observed in other genes causing autosomal recessive traits (60-70\%) and that most missense mutations in EPM 2A (9 out of 11 ) are clustered within exons 3 and 4 . These two exons of EPM 2A encode an amino acid sequence with significant homology to the catalytic domain of PTPases. ${ }^{10,11}$ Although no functional data is yet available for this putative enzymatic activity of the EPM $2 A$ gene product, the clustering of missense mutations suggests that the peptide region coded by exons 3 and 4 is crucial for the function of the EPM $2 \mathrm{~A}$ product, providing further support to the concept that EPM 2A indeed codes for a PTPase.

Among all EPM 2A mutations, the R241stop and G279S are present in Lafora disease chromosomes from different M editerranean regions. R241stop is the most prevalent EPM $2 \mathrm{~A}$ mutation. It is present in $23.5 \%(16 / 68)$ of EPM $2 A$ chromosomes and has been found in $32.5 \%$ of Spanish EPM $2 \mathrm{~A}$ chromosomes (13/40). A total of $40 \%$ of the Lafora disease patients carry this mutation. The analysis of the haplotypic associations of alleles at the EPM 2A-1, EPM2A-2, D6S1703, Laf-1, EPM2A-3, EPM2A-4, and EPM 2A-5 polymorphic sites demonstrated the existence of different EPM2A haplotypes associated with this mutation. One of them (189-166-149-A-160-159-199) is the most common haplotype associated with the R241Stop mutation (Table5). Our finding of distinct EPM 2A haplotypes associated with the R241Stop mutation suggest that R241stop has different phylogenetic origins and, therefore could be a recurrent mutation. Interestingly, analysis of the nucleotide sequence at this mutation site identifies a C PG dinucleotide. Moreover, analysis of the complete EPM $2 A$ sequence using the MUTPRED program ${ }^{14}$ denotes this site as a potential mutation hot spot, where c. $322 \mathrm{C}$ mutates to c. 322T, strongly supporting the concept that R241Stop is a recurrent mutation. The second most common mutation found in our family set, G279S, was associated with three different haplotypes and also coincides with a CpG dinucleotide, suggesting that it is a recurrent mutation too.

The Ex1-33bpdel (c.91-123del) is a mutation that has been encountered in only two unrelated families from one geographical Spanish region (Table5) and in all instances associated with identical EPM $2 A$ haplotypes. This argues in favour of a common origin for the EPM 2A chromosomes carrying the Ex1-33bpdel mutation. The fact that no variation is detected among these EPM 2A chromosomes suggests that Ex1-33bpdel originated recently.

The data presented in this article represent the first extensive account of EPM 2A mutations and associated polymorphisms and provide a general understanding of the variability at the EPM 2A locus in the Lafora disease patient population.

\section{Acknowledgements}

The authors wish to thank all the patients and family members who participated in this study. We also thank Dr D Lindhout, Dr PB
Augustijn, Dr CA Tassinari, Dr R Michelucci, Dr A Malafosse, Dr M Topcu, Dr D Grid, Dr C Dravet and Dr SF Berkovic for identifying Lafora disease patients. This work was supported by the Asociación Lafora España, the Fundación Jose Antonio de Castro, the Spanish Comisión Interministerial de Ciencia y Tecnología (SAF96/0318, SAF96/0055 and SAF99-0013-C02-02), the Fondo de Investigaciones Sanitarias (FIS98/0687), the Junta de Comunidades de Castilla-La Mancha and the Comunidad Autónoma de Madrid (08.6/0015/1997 and 08.5/0008/1998). P G-G was supported by a fellowship from the Association France Lafora.

\section{References}

1 Berkovic SF, Andermann F, Carpenter S et al: Progressive myoclonus epilepsies: specific causes and diagnosis. N Engl J Med 1986; 315: 296-305.

2 Lafora GR: Über das Vorkommen amyloider Körperchen im Innern der Ganglienzellen; zugleich ein zum Studium der amyloiden Substanz im Nervensystem. Virchows Arch. [Pathol. Anat.] 1911; 205: 295-303.

3 Lafora GR, Glueck B: Beitrag zur Histopathologie der myoklonischen Epilepsie. Z. Gesamte Neurol Psychiatr 1911; 6: 1-14.

4 Yokoi S, Austin J, Witmer F et al: Studies in myoclonus epilepsy (Lafora body forms). I. Isolation and preliminary characterization of Lafora bodies in two cases. Arch Neurol 1968; 19: 15-33.

5 Sakai M, Austin J, Witmer F et al: Studies in myoclonus epilepsy (Lafora body form). II. Polyglucosans in the systemic deposits of myoclonus epilepsy and in corpora amylacea. Neurology 1970; 20: 160-176.

6 Van Heycop Ten Ham MV: Lafora disease, a form of progressive myoclonus epilepsy. In: Vinken PJ and Bruin GW (eds). Handbook of Clinical Neurology, vol 15. North Holland: Amsterdam, 1974, pp 382-422.

7 Serratosa JM, Delgado-Escueta AV, Posada I et al: The gene for progressive myoclonus epilepsy of the Lafora type maps to chromosome6q. Hum Mol Genet 1995; 4: 1657-1663.

8 Gómez-Garre P, Anta B, Castro-Gago et al: Reduction of the Lafora disease candidate gene region to a $2 \mathrm{cM}$ interval in chromosome6q24 and evidence for genetic heterogeneity. Eur J Hum Genet 1998; 6: 152 (abstract).

9 Minassian BA, Sainz J, Serratosa JM et al: Genetic locus heterogeneity in Lafora's progressive myoclonus epilepsy. Ann N eurol 1999; 45: 262-265.

10 Minassian BA, Lee JR, Herbrick JA et al: Mutations in a gene coding a novel protein tyrosine phosphatase cause progressive myoclonus epilepsy. Nat Genet 1998; 20: 171-174.

11 Serratosa JM, Gómez-Garre P, Gallardo ME et al: A novel protein tyrosine phosphatase gene is mutated in progressive myoclonus epilepsy of the Lafora type (EPM2). Hum Mol Genet 1999; 8: 345-352.

12 Tassinari CA, Bureau-Paillas M, Dalla Bernardina B et al: La maladie de Lafora. Rev EEG Neurophysiol 1978; 8: 107-122.

13 Orita $M$, Iwahana $H$, Kanazawa $H$ et al: Detection of polymorphisms of human DNA by gel electrophoresis as single-strand conformation polymorphism. Proc Natl Acad Sci USA 1989; 86: 2766-2770.

14 Cooper DN, Krawczak M: The mutational spectrum of single basepair substitutions causing human genetic disease: patterns and predictions. Hum Genet 1990; 85: 55-74.

15 Ganesh S, Amano K, Delgado-Escueta AV et al: Isolation and characterization of mouse homologue for the human epilepsy gene, EPM2A. Biochem Biophys Res Commun 1999; 257: 24-28.

16 Minassian BA, Ianzano L, Delgado-Escueta AV, Scherer SW: Identification of new and common mutations in the EPM 2A gene in Lafora disease. Neurology 2000; 54: 488-490.

17 Dib C, Fauré S, Fizames C et al: A comprehensive genetic map of the human genome based on 5,264 microsatellites. Nature 1996; 380: 152-154. 